Article

\title{
When Care and Concern Are Not Enough: School Personnel's Development as Allies for Trans and Gender Non-Conforming Students
}

\author{
Robert A. Marx ${ }^{*}+$, Leah Marion Roberts ${ }^{*}+$ and Carol T. Nixon \\ Peabody College of Education and Human Development, Vanderbilt University, Peabody \#90, \\ 230 Appleton Place, Nashville, TN 37203-5721, USA; carol.t.nixon@vanderbilt.edu \\ * Correspondence: robert.a.marx@vanderbilt.edu (R.A.M.); leah.m.roberts@vanderbilt.edu (L.M.R.); \\ Tel.: +1-615-270-9502 (R.A.M.); +1-608-772-8824 (L.M.R.) \\ + These authors contributed equally. \\ Academic Editors: Maralee Mayberry and Lane Hanson \\ Received: 30 September 2016; Accepted: 20 January 2017; Published: 25 January 2017
}

\begin{abstract}
Trans people-and particularly trans youth—have come to the forefront of political and educational discussions, especially as legislation has aimed to ensure that school personnel act as enforcers of state-level policies targeting trans youth. For this reason, and because research demonstrates that youth in schools form attachments to and receive support from school personnel, our research looks at school personnel's development as allies. By analyzing focus group data following a training workshop, we explore how participants understand their roles as allies to trans and gender non-conforming youth. We found that trans issues were salient and participants expressed new knowledge about and openness towards transgender youth, as well as care and concern for their wellbeing. Nonetheless, many participants retained frames of understanding that relied on trans people as Other and that situated their roles as allies through the frameworks of protection and care. We argue that these understandings of trans youth and the role of allies reinforces cisnormativity, and we push for a more nuanced understanding of allyship that moves beyond knowledge, beliefs, attitudes and intended behaviors as markers of allyship to ensure that allies do not reproduce cisnormativity even in their support of trans and gender non-conforming youth.
\end{abstract}

Keywords: ally; ally development; trans and gender non-conforming; LGBTQ+; school personnel; training; professional development

\section{Introduction}

In reading the news over the past two years, one might be tempted to think that the most central aspect of trans people's identities is bathroom use: debates have flared concerning bills that would either ensure that anyone could use the bathroom in which they feel most comfortable or that one can only use the bathroom that corresponds to one's "birth gender" as found on their birth certificate [1]. In the American South, anti-trans bathroom bills in North Carolina, Arkansas, and Tennessee have pushed the conversation forward [2], as activists who might have focused on issues of police brutality, access to health care, or any number of other systemic injustices trans people face are instead arguing for the right to go to the bathroom without being singled out, surveilled, or put in danger.

This increased conversation about trans people and where they can and cannot go is now explicitly focused on trans youth; the proposed anti-trans bathroom bill in Tennessee, for example, targets students at public schools and universities [2], putting adolescents and youth in the crosshairs of political battles and public scrutiny. Because of these bills, public school students, teachers, counselors, and administrators who may not have otherwise considered their trans students' experiences are now 
being explicitly asked to enforce a restrictive and harmful interpretation of gender politics. In this and many other debates about gender expression—for example, gender policing of homecoming and prom courts, school uniform enforcement, or extracurricular activities-school personnel function as judge and jury. Thus, they shape and foster a school environment that can either support or damage trans and gender non-conforming youth, one that can disrupt or reinforce cisnormativity, affecting all students.

\subsection{Why School Personnel}

Both because of the external pressures on school personnel and because of the continual interactions between school personnel and students, teachers, counselors, and administrators at public schools have begun to play increasingly important roles in trans students' lives. Therefore, understanding if and how adults in schools see themselves as allies to their trans and gender non-conforming students is vital. Positive, supportive relationships between lesbian, gay, bisexual, transgender and queer $\left(\mathrm{LGBTQ}+{ }^{1}\right)$ students and school personnel have been shown to mediate negative outcomes for youth [3-6]. Therefore, understanding the ways in which these relationships may be formed and conceptualizing school personnel's views of allyship could have potentially far-reaching consequences for youth.

Many LGBTQ+ training modules have demonstrated increased attitudes, knowledge, and expected supportive behaviors of teachers towards LGBTQ+ students [7-15], but they have not explicitly focused on teachers' views of trans and gender non-conforming students. Trans and gender non-conforming students may rely on their teachers, counselors, and administrators to affirm their identities and model inclusivity-for example, by using their correct name and pronouns, providing gender inclusive bathrooms, or ensuring their safety in locker rooms when changing for physical education class. Therefore, it is imperative that we better understand the perspectives of adults in schools, especially their views of themselves as allies and their conception of what allyship entails. This increased understanding could help to create a cadre of allies who would proactively alter their own school climates to ensure that trans and gender non-conforming students were not systematically discriminated against and were free to learn, thrive, and grow. Moreover, a richer perspective on school personnel's views of allyship and of their own self-conceptions of their roles in the enforcement of the gender binary and heterosexism might not only inform trainings and pre-service education, but would also give researchers greater insight into how to operationalize and quantitatively measure allyship, especially for trans and gender non-conforming students.

It may be useful to situate school personnel's beliefs within a "queer school" [16] framework; that is, the notion that an ideal school does not reproduce traditional hegemonic binaries nor gloss over inequity by claiming that all students are equal, irrespective of their myriad differences. Core to the queer school model is the understanding that all people have a gender and sexual identity, rather than models of schooling that mark only LBGTQ+ members as having sexual orientations and relationships to gender. In order to better understand how to cultivate a school that undoes heterosexism and cisnormativity, we must first understand where school personnel currently are in their conceptualizations of gender identity and sexuality, and how these views may be in line with or run contrary to models of allyship.

\subsection{Ally Development}

Adult allies in schools are particularly important, as research suggests that relational dimensions such as perceived trust, support, and care positively impact students' behavioral and academic

1 Throughout the paper, we use the term LGBTQ+ as opposed to LGBTQ to capture that many people who exist outside of the heterosexual and gender binary paradigms (e.g., asexual, aromantic, pansexual, or two-spirit) but who do not identify specifically with the terms lesbian, gay, bisexual, transgender, or queer. 
outcomes $[17,18]$. The best practices in creating positive and supportive school climates recognize that LGBTQ+ students report feeling more supported and safer in schools where (1) gay-straight alliances or similar student groups exist; (2) staff actively disrupt LGBTQ+ harassment and bigoted language; (3) clear anti-bullying policies exist that explicitly protect against harassment based on sexual or gender identity/expression; and (4) school curricula include positive examples of LGBTQ+ figures and historical events [3]. Each of these best practices relies on the active support of school staff who understand themselves to be powerful allies who can meaningfully alter the school climate.

Much of the literature related to the formation of an ally identity establishes the central characteristics of an ally as one who has the knowledge, beliefs, attitudes, and intentions to help promote change and care for those in need [19-24]. These fundamental aspects of allyship are undeniably important; indeed, who could argue that one could be an ally to a trans student without knowing what cisgender means, or believing that trans students should be addressed by the name they identity with, or intending to behave in ways that affirm and celebrate trans youth? Although these models may be essential, they limit our vision of allyship to one's ability to care for and accept a non-dominant group. There is no room in these models to capture the need for an ally to understand their own role in societal structures that privilege their dominant position nor the need to move beyond knowledge and concern to a critical view of the systems in place that presuppose a dominant and subordinate group. In effect, these modes of allyship leave little room to assess the roles of allies in maintaining structural inequities on the one hand, or disrupting hegemonic assumptions such as cisnormativity on the other.

To that end, our understanding of allyship aligns with contemporary work that foregrounds the importance of social justice in the formation of allies. Edwards [25] offered a useful framework in which he posited three stages of allyship: self-interest, altruism, and social justice. He distinguished between allies who work because of personal connections to (self-interest) or concern for (altruism) marginalized groups and those who work for change because they see themselves implicated in and harmed by the oppression of others (social justice). His understanding, as well as the work of other scholars who put forth more nuanced notions of allyship, serve to demonstrate that an ally is more than a caring person who works to help troubled youth [26,27]. Our conception of allyship draws on this important distinction between those who simply care for others and those who are invested in social justice and a radical restructuring of society to work against systems of oppression.

We explicitly draw on previous researchers' work with anti-heterosexist and anti-cissexist ally development models grounded in the destabilization of hierarchies that privilege heterosexual and cisgender identities and that attempted to render manifest, and therefore de-constructible, the gender binary [28,29]. Mohr posited a developmental model that brought about such awareness, as he documented the transition from democratic heterosexuality-a view focused on equality and sameness of all sexual identities - to integrative heterosexuality - a view that recognized the privilege inherent in a heterosexual identity and the ways in which all sexual identities are part and parcel of an oppressive, hegemonic system that is damaging for all, although unequally [30].

In this way, we were guided by the understanding that in order to dismantle the cissexist patriarchy, we must move beyond discussions that position one group as dominant and everyone else as Other, or as lesser, different, or marked. Maintaining trans and gender non-conforming youth as Other renders them legible only in their comparison to the dominant, cisgender youth and only serves to privilege and reinforce cisnormative structures [31-34]. This pattern is mirrored in divides that are often created between LGBTQ+ and heterosexual youth, as "queer- and heterosexual-identified youth often find themselves in untenable situations, increasingly defined by a dynamic that somehow manages to promote the utility of separating 'queer' and 'normal' young people" ([35], p. 2). Additionally, because youth at all ages are working through issues of gender and sexuality, we were especially attentive to work that centered discussions with teachers about gender and sexuality for youth often deemed 'too young' to understand such complex or mature issues [36].

Much of the research following LGBTQ+ ally training has documented the creation of heterosexual allies who had greater knowledge, lower levels of homophobia, and attainable goals for 
allyship [7,21,37-39]. However, more recent research has shown that careful examination of participants' commentary following a highly intentional anti-heterosexist training demonstrated that although participants espoused increased knowledge and radical reformation, their words fit neatly into their previous paradigms and belied the progress they claimed [28]. This close attention to the intricacies of potential allies' commentary, especially as it related to participants' accommodation or transformation of their interpretive schema for allyship, provides an important lens for understanding participants' ally development.

Notably, the literature on ally development has not spoken to the cultivation of cisgender allies to trans youth. Although much of the training evaluation and allyship development research has focused on LGBTQ+ ally development, to date, none has focused exclusively on the development of allies for trans youth.

\subsection{The Current Study}

This study aims to contribute to the knowledge base surrounding ally development, especially as it applies to adult allies of trans and gender non-conforming youth in schools. We conducted a qualitative analysis of existing focus group data that were collected following a full-day summer training workshop designed to support teachers and other school personnel as allies for youth who identified as LBGTQ+. Specifically, our analysis explored the following research questions: (1) How salient was the topic of trans students' identities? (2) How did participants discuss their understandings of trans students' identities and issues related to being trans in school? (3) What did participants see as their relationship to students, especially as related to trans students? (4) How did participants describe their own roles as allies, and what responsibilities did they perceive accompanied those roles? (5) What tensions or contradictions were present in participants' conceptualizations of their roles as allies for trans youths? and (6) To what extent did participants' comments demonstrate a disruption of the gender binary or an understanding of heterosexism and cissexism? We expected to find a range of participants' understandings of allyship related to student identity and a variety of perspectives, all of which would inform our understanding of how school personnel conceptualize and discuss these issues in order to inform future professional development and school-level interventions, as well as research.

\section{Methods}

\subsection{Design}

This project is a secondary analysis of focus group data collected as part of a larger longitudinal evaluation of a full-day, summer workshop offered by a large, urban, southeastern district and its community partners to secondary school teachers and other K-12 support personnel (e.g., school counselors, psychologists). The evaluation was approved by Vanderbilt's Institutional Review Board as well as the school district.

\subsection{Context: Training Design and Content}

As part of its ongoing school climate improvement efforts, the school district and its community partners offered two, eight-hour training workshops in the summer for teachers and other personnel to strengthen their skills as allies for marginalized students, particularly those who identify as LGBTQ+. These workshops were designed as a follow-up to an initial phase of training over the prior two years in which the district asked all secondary school teachers to attend a one-hour training designed to support LGBTQ+ students. Although the organizers conceived of the training as LGBTQ+ focused, the recruitment materials made no mention of queer topics specifically, as the program was titled Creating an Open and Affirming School: Navigating Student Safety in a Culturally Diverse Classroom, Part 2 and only referred to culturally diverse classrooms and open and affirming school climates. 
The current training was designed to provide personnel with deeper knowledge and skills and particularly to cultivate active allies who work to undo heterosexist and cissexist practices present in the school environment and their larger social context. The first segment of the training offered participants space to reflect on their own multiple, intersectional identities and positionalities; to understand the cycle of socialization [40]; and to explore their own values as they relate to gender and sexuality, with particular attention to how their values enter into their professional work. The next segment focused specifically on the school district and debuted a locally-produced video featuring voices of the district's students and personnel. We also included interactive discussions with trans youth to both increase participants' knowledge of trans youths' experiences and their openness to LBGTQ+ people. Over lunch, participants chose one of the following discussion groups: (1) religion, gender and sexuality; (2) trans and gender non-conforming youth; or (3) LGBTQ+ inclusive lesson planning. In the final training segment, participants learned in depth about the diversity of gender identity, gender expression, biological sex, sexuality, physical attraction, and romantic attraction. After an interactive discussion of micro-aggressions and interrupting hetero/cissexist behavior and hetero/cisnormativity assumptions, participants were given the opportunity to put their learning to practice with scenarios and role plays. In total, the interactive training aimed to provide an expansive understanding of sexuality and gender, the diversity of LGBTQ+ student experience, and the intersections of race, class, language, religion, gender, ability, and sexuality on student and educator experiences.

\subsection{Participants}

Training participants were recruited by district counseling personnel using emailed flyers and follow-up information. Attendance was voluntary and attendees received professional development credits and a daily stipend by the school district. Participants for the evaluation were recruited during each morning registration. During registration, participants were informed of the study and asked if they would like to know more. If so, a member of the evaluation team described all aspects of the evaluation in detail and obtained written informed consent if trainees agreed to be included in the evaluation. Evaluation participants were provided a $\$ 30$ gift card to compensate them for their time. The decision to participate in the research did not affect professional development credit or payment from the school district. Forty-six of 49 trainees (94\%) consented to participate in the evaluation. Because evaluation activities were embedded during the training day, non-participants were given alternative activities. The participants included one administrator, 22 teachers (one elementary, 21 secondary), and 23 certificated staff (14 school counselors, six school psychologists, three special education coaches). About half of the participants (52\%) preregistered for one of the trainings. Eighty percent identified as female and $20 \%$ as male. Forty-five of the 46 participants self-identified as "straight/heterosexual," and one participant self-identified as "not straight" (e.g., lesbian, bisexual, gay, queer, pansexual, asexual).

\subsection{Data Collection Procedures}

We conducted 10 focus groups of four to six participants each immediately following the end of training each day. Prior to the day's training, researchers numbered blank nametags to assign participants to the 10 focus groups systematically and in an unbiased way. Groups were initially kept small in order to encourage participation. Trained university research assistants and faculty facilitated the focus groups using a semi-structured focus group guide that included questions and follow-up prompts organized around four primary topics: (1) reflections on the training (e.g., "What did you think of the training today?" and "What was the most challenging or difficult part of the training?"); (2) transfer of learning from training (e.g., "How do you plan to use what you learned today?"); (3) shifting perspectives/attitudes (e.g., "Did the experience make you feel differently about yourself, your classroom, or your school?"; and (4) capacity to serve as an ally to LGBTQ+ youth (e.g., "Do you feel more empowered to serve as an ally to LGBTQ students? Why or why not?"). Focus groups were audio recorded and then transcribed verbatim by a transcription service. 


\subsection{Data Analysis}

Using the existing focus group transcripts, two of the authors (R.A.M. and L.M.R.) independently coded the transcripts using the constant comparative method to form codes and categories [41]. We met to compare coding and resolved all discrepancies to reach consensus. We sought to let themes emerge from the data in a grounded way, while also paying particular attention to (1) the ways in which participants understood gender; (2) moments that would be indicative of ally development including reference to: new knowledge, change in attitudes, openness towards trans and gender non-conforming youth, or intended behavior; and (3) moments that reinforced or challenged cisnormativity and gender policing. Additionally, we paid special attention in our analysis both to language and to the internal logics of the participants' views on allyship and trans people and gender norms.

\section{Results}

Our final coding scheme highlighted three overarching themes: (1) new allies: trans salience and awareness; (2) maintaining cisnormativity; and (3) moments of resistance: cisnormativity challenged. In particular, the data suggested participants maintained cisnormativity primarily by (a) maintaining trans people as Other and (b) conceiving of themselves as "altruistic allies" [25]. In the following sections, we elaborate on each providing illustrative comments from focus group participants.

\subsection{New Allies: Trans Salience and Awareness}

Our data suggest that participants in our study saw themselves as new allies to LGBTQ+ youth, and trans youth in particular. Throughout the focus groups, they reflected on both the very general-today was "reinforcing of what we need to do for all children who may live within the margins" - and the highly specific - "we have kids that all day long every day don't go to the bathroom" - aspects of what they learned and believed about trans people's lives within classrooms and communities. As seen in the last quotation, themes related to the experiences of trans youth emerged as particularly salient in participants' discussions. Each focus group reflected on, and often lingered on, trans issues as they processed the day's training. Most notably, the focus group guide questions did not ask participants to comment, directly or indirectly, on any specific aspect of the training, nor did they ask directly about gender or trans students. Rather, in an attempt to give voice to participants, the questions gave participants wide latitude to comment on any aspect of the training or on their roles allies to LGBTQ+ youth. The frequency with which participants mentioned trans students serve to highlight how ripe educators and other school personnel in our study were for conversations about trans and gender non-conforming students' experience.

Reinforcing the salience of trans issues, these focus groups highlighted the extent to which trans people have penetrated the public consciousness. Many participants brought in outside knowledge and examples of trans people with whom they were familiar, for example naming Laverne Cox, Jazz Jennings, Caitlyn Jenner, Chaz Bono, and other celebrities as entry points into the conversation about trans people's lives. One participant also referenced the public discourse around trans people, saying, "I just watched an episode of Fatal Attraction about that." This continued reinforcement that the main learning took place around issues of gender identity and expression served to underscore how salient trans issues are for this group, as it demonstrated their focus on and interaction with some aspects of gender.

Not only did participants find trans people and issues around gender identity and expression salient, but they also expressed new knowledge about and openness towards transgender people. Participants noted that the training was "informative," "enlightening," "challenging," "surprising," and "eye-opening" in relation to gender identity and issues that impact trans students such as pronouns, bathrooms, gender identity development milestones, and more.

Participants offered specific ways in which the training increased their awareness of and shifted their perspectives about trans people and their roles as educators. As one participant shared, "I didn't, 
I really didn't know anything about trans [sic], aside from what's going on you know, publicly in the media and in Hollywood. So it was great to kind of hear some actual factual information." Another participant elaborated, "I've been kind of blind and just thinking it's [trans people are] just you know, the media Hollywood type of thing, and to see young people you know, and in [our] schools you know, dealing with that, is like okay...very eye-opening." Another participant offered critical reflection on their ${ }^{2}$ behavior and potential mis-gendering of those they interact with, saying,

The pronoun, the personal pronoun usage thing. That's just something I don't think would have thought of and yet in, in moments maybe you, you're not sure how to respond or react, but you don't realize how many things that maybe, you just are offensive to someone or made someone feel uncomfortable when you certainly would not want to.

Their expressed understanding of the ways in which they may have hurt or offended others through an assumption of personal pronouns demonstrates a clearer understanding of the trans experience and a willingness to learn.

\subsection{Maintaining Cisnormativity}

The above section explored the ways in which participants were open and embracing of trans people, potentially signaling their allyship to trans youth. However, embedded within the overall positive reception of trans identities are several logics and ideologies that maintain and normalize cisgender and gender binary assumptions that many ally development frameworks might miss. To demonstrate this, this section will look closely at (1) how participants understood trans people and positioned them as Other and (2) how participants understood the criteria for allyship, which relied on a limited vision of care and protection for individual students, and an erasure of both the specific and general ways that gender norms impact students. In the following sections, we describe these findings in more detail.

\subsubsection{Maintaining Trans People as Other}

Despite the participants' expressed desire to be allies to trans individuals as well as their awareness of and sensitivity to trans issues, many participants maintained trans people as Other rather than challenging the systems and practices that may perpetuate inequity and violence. In our data, participants most often understood trans people in contrast to cisgender and gender-conforming people and rendered them acceptable only through their approximation to normative gender standards. Participants maintained trans people as Other in two primary ways: (1) explicit articulations of trans people as Other or "strange," especially when they did not conform to particular expectations of acceptability and (2) the use of narrative frameworks that represented trans youth through pain and victimization. These are elaborated in detail to follow.

Maintaining the Other: Trans People as Strange

One way in which participants maintained trans and gender non-conforming youth as Other was to label them as "strange" or to couch their acceptance of trans people by insisting or insinuating that (some) trans people are inferior. One participant expressed a particularly poignant example of how transgender youth, along with other LGBTQ+ youth, were maintained as Other, even as the participant purported to be an ally. He said, "my school already has a club...we're more accepting of people who are, let's say strange and different or diverse." This conflation of diversity and strangeness, especially as it is juxtaposed against the "more accepting" nature of the school, makes apparent that he feels supportive, or at least tolerant, of queer and trans young people-and therefore could maybe be seen

2 We alternate between the singular they, she, and he as pronouns to refer to research participants. The gender pronouns used for participants do not necessarily match the focus group participants' gender identities. 
as an ally-yet he can only see them as outside of a perceived 'normal' group of students. Not only does this perpetuate divisions between trans and cis students, it also defines the norm through cis students' experiences and realities which trans people then are compared to. Whether consciously or not, this respondent seems to believe that queer and trans students are "strange and different" rather than a welcomed expression of diversity, and that having a school club alone creates acceptance, as if a school merely needed to check such programs off a list in order to be accepting.

The presumed strangeness or otherness of trans people reinforces the idea that trans people are different than their cisgender peers in a problematic way. Some participants espoused the idea that as trans and gender non-conforming people approximate particular standards of normalcy they will be seen as more fully acceptable. These ideas further marked trans people as Other by only rendering them intelligible in contrast to their normal peers. In a conversation among several respondents who were working together to explain what they felt was a nuanced call for more positive trans representation, the respondents in truth exemplified their desire for trans people to conform to particular standards of acceptability. Their interchange demonstrated this:

R1: As far as breaking down barriers, when I was growing up my only association [with trans and gender non-conforming people] that I can remember...was like what you see on TV like RuPaul and things like that, people who are really showy and flashy and draw this attention you know I think that's what's led to the negative backlash with transgender [people] for a period of time like nineties and you know late eighties, you know so if we could get [pause] more [pause]

R2: Positive images.

R1: Yea, that's what I'm trying to think of.

R3: Normalizing it a bit more.

R1: Well, I don't want to say normal, but just not so...

R3: Dramatic?

R1: Yeah.

Although the respondents worked together to co-create a corrective narrative for trans people in popular culture and explore the "negative backlash" against trans people, they revealed several transphobic tropes: that trans people are seeking attention, flashy, dramatic, and abnormal. Even as Respondent 1 eschewed the labeling of 'normal,' he seemed to accept the notion that trans people should be less dramatic as a means of overcoming negative backlash. In other words, although these participants openly expressed their support for trans individuals, these positive perceptions only held for certain kinds of trans individuals-individuals who conformed to an ideal of acceptability. Later in this same focus group, participants explained that they wanted to see "good role models," "individuals without the drama," and more "subtle" versions of LGB people generally, and trans people specifically. Although an appeal to role models may seem innocuous, put in context, these coded statements potentially expose a desire to only accept transgender individuals as they approximate and blend in with cisgender individuals and otherwise conform to normalcy.

In a refreshing moment, one participant picked up on what she perceived to be the hypocrisy some of her fellow participants' remarks. Offering direct feedback to her peers, she remarked

[she was surprised by] how many people were willing to say basically, "I'm fine with transgender people, they should just not use the bathroom. I just, I have to, I have to make some weird, complicated exception so I can talk about how uncomfortable I am having them in my bathroom"...we are willing to project a lot of our social fears about physical safety, sexual assault onto transgender people and bathrooms.

This statement shed light on the ways in which her peers were contorting themselves to simultaneously purport to be trans inclusive but also to espouse views that would exclude and inhibit trans people's participation in daily life and schooling by making trans people's needs, and therefore trans people, 
into something to be feared. This was certainly one of the more nuanced understandings of trans issues noted in any of the focus groups.

Maintaining the Other: Damage and Victimization

Respondents often framed trans existence as marginal, damaged, and marked by trauma. This stood in contrast to our intentional design of the program to avoid "damage-centered" [42] frameworks. For instance, one participant said, "this is a group that's been marginalized as well and they need to be included in that bullying aspect because that's an important piece as well." While it is clear that trans students may face increased bullying and may be marginalized in schools [3], the respondent frames their understanding of trans youth only in terms of existing frames of marginalization and bullying, rather than in other, more positive frames associated with youth, such as joy, romance, or laughter, or in newly created frames that accommodate more aspects of trans existence. This singular framework of pain is further typified in one exchange between two respondents:

R1: I attended the struggling one, the first one. What was it called?

R2: The transgender, trans one.

R1: Yea, the first one.

Even after asking for the name of the session, the respondent resisted using the word trans to describe the session and instead conflated of the trans session with the "struggling" session.

Not only does this framing demand that trans young people are understood as separate from their cisgender peers, it also insists that their value as students is made possible through their trauma, thus "the complexity of queer [and trans] youths' subjectivity, agency, sexuality, and cultural practices is flatted by a dominant framing of them in terms of danger and victimization" ([35], p. 7). This singular 'at risk' narrative positions trans young people as separate from their 'normal' and 'healthy' cisgender peers-a discursive pattern that reproduces a divide between trans and cis students, and maintains trans youth as Other [43]. Participants' framings of the experience through pain and trauma may offer them readily accessible points of relationship with trans youth (as will be explored in the next section), but it also may limit the fullness and richness of experience that trans people can share, especially as they may be understood only in relation to a dominant, oppressive force. This focus on the pain and suffering that trans youth experience serves to present a singular and simplistic frame as oppressed Other through which all trans identities are understood. Further examples of the damage and victimization frames will be explored in the next section, as seeing trans youth in this way seemed to be essential to participants' understanding of their roles as allies.

\subsection{2. "Altruistic Allies": Limits of Protection, Care, and Equality}

In this section, we draw on the frameworks that participants used to position trans people as Other and we closely examine how participants' frame allyship-what did it mean to these participants to be an ally? Our data suggest that participants saw their roles as allies as (1) a duty to protect and care for (victimized) trans individuals and (2) a generalized call to care equally for all students. We argue that these conceptualizations of allyship allow participants to position themselves as unbiased, caring allies, while leaving their perpetuation of cisnormativity unchallenged.

Allyship as Care and Protection

The damage-centered appeals of risk and victimization of trans youth that we explored above were taken up by the participants' as they framed their roles as allies as supporters and protectors of trans youth. The framing of trans individuals as only intelligible through trauma, pain, and suffering led to an understanding of trans peoples as victims who are in need of protection and care [44]. For example, one respondent commented:

to hear the things that they were saying. And some of it, the trials and tribulations that they have gone through, and you as a mom to talk about the challenges that your child 
faced and you just want to make sure you know as an educator you want to provide, you know, a safe place for them to be, to feel supported and accepted.

This respondent articulated empathy and compassion for the difficult experiences that trans youth and their parents face. This understanding of what it means to be an ally might be understood as an "aspiring ally for altruism" [25] where allyship is viewed as a compassionate duty to help a victimized Other. This respondent, and the many others who offered similar insights about the difficulties associated with trans adolescence and the need for safety, support, and acceptance, serves to further frame trans youth as inherently damaged, troubled, and in need of shielding and safety, which maintains their position as Other, as we previously noted. The framing also uses this position of trans young people to claim the respondent's role as protector, which is a limited view of allyship. We assert that one must be careful not only to assume the role of caretaker, as that presupposes that trans youth are always damaged or in need of protection.

Allyship as Reacting to Individual Students

Implicit in allies' conception of their role as caregiver and protector is an understanding that allyship manifests itself only in relation to particular cases. To be an "aspiring ally for altruism" [25], participants conceptualized their capacity to act as an ally through their imagined responses to individual trans and gender non-conforming-identified students. This effectively requires an "out" student to be present in order to activate their allyship which ignores the way that gender is imbued into and reinforced in school culture, regardless of individual students' identities. For example, another participant commented:

I haven't had a student yet to tell me that they're transgender, but making sure as a counselor that I deal with that, that I react to that appropriately, making sure that I'm being supported and not passing my own personal vices, if I have any, I hope I don't, but still you want to make sure that you don't want to, that you want to be supportive and you want to say the right thing.

This participant clearly expressed their concern to provide care for and to support any transgender young person that they may encounter, and at first blush it seems like a concrete example of a participant expressing allyship. However, this statement exemplifies the common assumption that the only time when conversations about gender are going to impact the young people that they work with is when a young person comes directly to them to discuss their gender identity and expression.

Additionally, this identity-based understanding of allyship prompted several comments about how about how the training was informative yet would not apply to their work because they did not anticipate trans students interacting in their spaces, as seen when the respondent commented "I haven't had a student yet to tell me that they're transgender." In another example, one respondent said: "Part of me kind of felt like it wasn't really helpful, because I'm an elementary person." Assuming that gender and sexuality topics would be irrelevant for elementary students grossly misrepresents the notion that gender and sexuality always shape our social world, even if there are not 'out' trans people at school. The participant incorrectly assumes that elementary students do not think about, learn about, or confront gender and sexuality in their everyday lives (e.g., being teased for "acting like a girl," reading a book about a family with heterosexual or cisgender parents which does not reflect their own family, or being split up for activities into 'boys' and 'girls').

Allyship as Equality for All

In addition to erasing the ways in which gender norms impact youth even when there are not 'out' trans students at school, participants additionally erased the complexities and particularities of being an ally for gender-justice by appealing to their roles as protector of 'all students.' Many respondents offered comments that their primary job is to care for all their students, to treat them equally, and to offer support to everyone. This equal care was seen as evidence for allyship. For example, one respondent 
said, "I feel like I'm an ally for probably any student who's processing or needs an ally, not just one specific group but all groups." This statement is presented as a reasoned example of ideal educators, who do not exclude, for example, transgender students from their care. Yet it also effaces important differences between people and represents allyship as a single, static construct. By offering, as one respondent did, that "people are just people at the end of the day," or other representations of allyship as seeing everyone equally, participants effectively identify themselves as allies—or perhaps more appropriately, as people who are not guilty of bigotry or bias-yet evade any responsibility for gender or sexual inequities. When a participant says that she would treat all students the same or care for a trans student just like she would care for any other student, she willfully ignores the differences that may in fact require her to see and acknowledge a trans student as differently impacted by gender norms. Appealing to the 'sameness' of 'all students' reinforces cisnormativity by minimizing the particularities that are essential to trans and gender non-conforming students' experiences. When differences are flattened, the dominant, normative conceptualization of gender goes unchallenged, allowing it to maintain its dominance even while difference is tolerated and anti-discrimination values are enforced.

\subsection{Moments of Resistance: Cisnormativity Challenged}

In contrast to the previous examples in which participants maintained cisnormativity through their reliance on understanding trans students as problematic Others, some participants challenged these assumptions and expressed a desire to disrupt cisnormativity. In these moments, participants gave concrete examples of practices that would challenge normative assumptions about the gender binary, while simultaneously affirming the experiences and identities of trans and gender non-conforming youth. One way that participants did this was by suggesting that they would introduce the practice of allowing people to claim the pronouns that they identity with in their classrooms and staff meetings. For example, one respondent stated, "I'm going to start by saying my name is and my pronouns are." Another participant said:

I'm going to start the first day of school out with introducing myself and say which pronouns that I use and ask each student to introduce themselves and use the pronouns that they were, say the pronouns they'd like for us to use addressing them with the name they want to be called.

These practices have the potential to disrupt cisnormativity because they do not assume the gender identity of others, but do assume that everyone has a gender identity. However, in the latter case, the participant furthered his statement when he said, "I mean in my school it's, that'll be like oh wow, you know, the kids will be very relieved because most of the kids are part of that community." This makes clear that although the practice of addressing names and pronouns with students in school for everyone has the potential to challenge norms about gender, this participant still sees the value of this process mostly for the benefit of his trans and gender non-conforming students. This belief is not inherently wrong, but it maintains the notion that disrupting normative assumptions about gender is only necessary when trans people are present.

In addition to challenging assumptions about what pronouns people will use, another participant challenged the ways in which bathrooms reinforce the gender binary by committing to advocate for all gender bathrooms in her school: "I plan to bring in the morning meetings [with other school personnel], bring in the unisex bathroom, where, you know, students have a choice that's not pre-identified for them." Importantly, in this example, the participant did not frame the concern for inclusive bathrooms solely in relation to protecting an individual student who needs a bathroom accommodation. Rather, she positioned this concern about bathrooms as problematic because it presupposes and attempts to manage where students will go to the bathroom, in a way that reinforces assumptions about the legibility of students' gender expression. 


\section{Discussion}

Our results indicate that the school personnel in our study would fit within several models of allyship. In this sense, they could be considered new allies to trans youth because they developed new knowledge and positive ideas about trans people and demonstrated considerable openness to learn and grow. Yet, our results also demonstrate that many participants continued to position trans youth as Other, even as they suggested that they were supportive of trans youth, and their ideas of allyship were generally limited to an "altruistic" [25] framework. The frameworks that the vast number of our participants used to understand trans people and allyship left cisnormativity unchallenged, a notion that many ally development models are not equipped to highlight or accommodate. Even so, we also noted encouraging moments where school personnel signaled intentions as allies that would actively disrupt cisnormativity.

Our findings have theoretical and research implications, as well as practice-based implications for the development of school personnel as allies for trans and gender non-conforming youth. As noted earlier, it is imperative that school personnel act as allies for LGBTQ+ youth, as these relationships can positively impact these youths' experiences at school [3-6]. However, research that has examined the ally development in the context of LGBTQ+ youth has mostly focused on increased attitudes, knowledge, and expected supportive behaviors of teachers [7-15]. Our research suggests that these outcomes of interest are limited, as our data demonstrate that school personnel evidenced these characteristics even while they maintained cisnormativity.

Our findings additionally have practical implications for districts that are working to improve their school climates for those who identify as LGBTQ+, and most relevantly here, those youth who identify as trans or gender non-conforming. As mentioned previously, the school personnel training was a component of a comprehensive, ongoing effort by the school district to measure and intervene to intentionally improve all students' perceptions of school climate within their schools. As more schools and school districts become interested in improving school climate and cultivating affirming environments for LGBTQ+ students and specifically trans and gender non-conforming youth, we believe that they will benefit from this research. Our findings have practical implications for how schools conduct future professional development trainings, how they evaluate their staff as allies for young people, and specifically the messages that they may send to staff about what it means to be an ally to trans and gender non-conforming youth.

We recognize, as many researches have before us, that adult learning happens experientially and contextually [45], through iterative processes [46], and that ally development is a process that may consist of stages [25,47] over time. As such, our concern is less that school personnel are imperfect allies to trans young people, but rather that their own understandings of allyship-which is reflected in much LGBTQ+ ally development literature which focuses on attitudes, knowledge, and expected supportive behaviors-limit their understanding of what an ally should be, and therefore allows cisnormativity to be perpetuated. Therefore, these findings suggest professional development needs to move beyond more traditional, one-time, content-heavy training sessions to incorporate experience, dialogue, and reflection, thereby providing more scaffolding to support meaningful development of allyship [48].

Our study had several strengths that distinguish its contribution to the literature. Firstly, to our knowledge, it is the first discussion of adult ally development focused specifically on school personnel's understandings of trans and gender non-conforming students, rather than all LGBTQ+ students as a singular group. Because our work draws on qualitative, focus group data, it offers a rich and complex description of adult ally development and allows greater insight into the thoughts and perceptions of our participants. Additionally, as the focus group questions did not guide participants to discuss trans and gender non-conforming students, the salience of and interest in topics about trans students were not artificially induced by leading questions. Moreover, because it was grounded in several models of ally development, the study offers a unique opportunity to discuss the potential shortcomings of models that situate care and concern as the primary obligation of allies, and it allows us to push for 
models that interrogate the maintenance of cisnormativity through such limited, altruistic frames [25]. Finally, as our research was situated within the school and professional development environment, it provides natural commentary on future directions for such programs, especially as they target teachers, school counselors, and administrators.

However, this study has several limitations that are important to note as they relate to generalizability of our findings and their applicability in other spaces. Our work is based on focus groups following a single training in a large, urban, relatively diverse school district. Further, this district is located in a highly conservative, southeastern state, and the prevailing opinions and conceptions at work in our sample may not represent views or conceptualizations held in demographically different parts of the country, or even in more rural areas of our own state. Moreover, although we attempted to ask broad questions that allowed participants to offer their own interpretations and find their own voices, responses may have been influenced by the design of the focus group guide, which was primarily used to assess the effectiveness of the training, rather than school personnel's views on trans students. It is also important to note the volunteer bias that may influence these findings; participants who signed up for a training addressing cultural diversity and affirmative classrooms may be qualitatively different from school personnel who did not. Nonetheless, while some volunteer bias may exist, it was likely mitigated by the inclusive and broad nature of the recruitment materials. Moreover, some participants attended at the requests of their administrators, unaware of the topic.

Future work should first expand its scope to other areas of the country and to school personnel who teach in different demographic and cultural environments. Moreover, research should examine the differences and similarities of perspectives along roles within schools to better understand if teachers, counselors, administrators, and other personnel approach these topics in importantly different ways. An additional avenue of study may include the examination of resistant school personnel; understanding how those who are unwilling to engage with LBGTQ+ topics or who actively espouse homophobic and transphobic beliefs may bring another important layer to this discussion. It may also be fruitful to link this expanded qualitative work to other data sources. For example, a mixed-methods study that incorporated measures of ally development, conformity to cisnormativity, and awareness of the ubiquity of gender roles would offer important new insights. Additionally, objective measures of participants' homophobic or transphobic beliefs may be useful in the design of future trainings and interventions. This addition may help explain whether underlying phobic beliefs shape participants' perceptions of themselves as allies, or if the limited conceptualizations of allyship that our findings highlight persist even in the absence of phobic beliefs. Further, the data from this study could inform revised conceptual models and frameworks of ally development, especially as it relates to LGBTQ+, and specifically trans and gender non-conforming students. Another natural next step for this research is for it to be utilized to redesign professional development supporting allyship development. Educational best practices demonstrate that adults need experiential, problem-centered learning opportunities that have immediate relevance to their own lives [45] and that adults benefit from repeated, iterative cycles of concrete experience, reflective observation, abstract conceptualization, and active experimentation [46]. Bringing together this literature with our work on ally development would offer additional insight into the cultivation of adult leaders and provide additional resources for those interested in training and professional development.

\section{Conclusions}

In times where the bodily autonomy, human rights, and freedoms of trans people and trans youth are being violated nationally, and particularly in the South, we are heartened by the overall positive and supportive messages that focus group participants expressed after the training. We are particularly impressed by the salience of transgender issues among responses considering that our focus group questions were open-ended, and while the training certainly covered gender issues and transgender students' needs and experiences, it was far from the only focus of our training. To us, these results signal the importance of discussing trans issues with school personnel, and their eagerness 
to think through how transgender issues impact their practice. Moreover, a few of the participants demonstrated critical awareness of the systems of oppression that reinforce the gender binary and cissexist privilege, a truly encouraging finding.

Nonetheless, it is important to couch this interest in and awareness of trans students' lives in the context of the participants' own understanding of their roles, which often demonstrated their maintenance of cisnormative systems of oppression and their understanding of an ally as one who cares for the trans student in front of them, rather than one who acts to dismantle the structure that allows the continued oppression of trans students. Indeed, cultivating a generation of allies who not only understand the gender binary but also recognize their own role in its reinforcement or subversion is a challenging, yet necessary goal as we seek to provide youth with affirming school environments in which to grow and thrive. It is our hope that this work helps us to move beyond the traditional models of allyship that focus on care, concern, and knowledge and enable us to actively interrogate how allyship undoes systems of oppression.

Acknowledgments: We would like to acknowledge and extend our deep gratitude to Nicole Cobb, Executive Director of School Counseling Services for Metro Nashville Public Schools (MNPS), and Pamela Sheffer, Program Director of LGBTQ+ Services at Oasis Center. Both were influential in the vision, design, development, and implementation of the ally development training. Without their passion, dedication, and expertise, this project would not have been possible. This research was supported by a contract to C.T.N. from MNPS as a part of its school climate improvement initiatives funded by the U.S., Department of Education's Safe and Supportive Schools program [grant number 2-218740-19].

Author Contributions: The co-first authors of this manuscript (R.A.M. and L.M.R.) conceived of the research questions as a secondary data analysis for this paper. Additionally, R.A.M and L.M.R. analyzed the data. R.A.M. and L.M.R. wrote the paper with contributions and full approval from C.T.N.

Conflicts of Interest: The authors declare no conflict of interest. The founding sponsors had no role in the design of the study; in the collection, analyses, or interpretation of data; in the writing of the manuscript, and in the decision to publish the results.

\section{References}

1. Gersen, Jeannie Suk. "The Transgender Bathroom Debate and the Looming Title IX Crisis." The New Yorker, 24 May 2016. Available online: http:/ / www.newyorker.com/news/news-desk/public-bathroom-regulationscould-create-a-title-ix-crisis (accessed on 30 August 2016).

2. Wang, Timothy, Sophia Geffen, and Sean Cahill. “The Current Wave of Anti-LGBT Legislation: Historical Context and Implications for LGBT Health." The Fenway Institute, June 2016. Available online: http: / fenwayhealth. org/wp-content/uploads/The-Fenway-Institute-Religious-Exemption-Brief-June-2016.pdf (accessed on 30 August 2016).

3. Kosciw, Joseph G., Emily A. Greytak, Neal A. Palmer, and Madelyn J. Boesen. "The 2013 National School Climate Survey: The Experiences of Lesbian, Gay, Bisexual and Transgender Youth in Our Nation's Schools." GLSEN, 2014. Available online: https://www.glsen.org/sites/default/files/2013\%20National\%20School\% 20Climate\%20Survey\%20Full\%20Report_0.pdf (accessed on 30 August 2016).

4. Murdock, Tamera B., and Megan B. Bolch. "Risk and Protective Factors for Poor School Adjustment in Lesbian, Gay, and Bisexual (LGB) High School Youth: Variable and Person-Centered Analyses." Psychology in the Schools 42 (2005): 159-72. [CrossRef]

5. Munoz-Plaza, Corrine, Sandra C. Quinn, and Kathleen A. Rounds. "Lesbian, gay, bisexual and transgender students: Perceived social support in the high school environment." The High School Journal 85 (2002): 52-63. [CrossRef]

6. McGuire, Jenifer K., Charles R. Anderson, Russell B. Toomey, and Stephen T. Russell. "School climate for transgender youth: A mixed method investigation of student experiences and school responses." Journal of Youth and Adolescence 39 (2010): 1175-88. [CrossRef] [PubMed]

7. Athanases, Steven Z., and Timothy G. Larrabee. "Toward a consistent stance in teaching for equity: Learning to advocate for lesbian-and gay-identified youth." Teaching and Teacher Education 19 (2003): 237-61. [CrossRef]

8. Butler, Karen L. "Preservice Teachers' Knowledge and Attitudes Regarding Gay Men and Lesbians: The Impact of a Cognitive Educational Intervention." American Journal of Health Education 30 (1999): 126-30. 
9. Dessel, Adrienne B. "Effects of intergroup dialogue: Public school teachers and sexual orientation prejudice." Small Group Research 41 (2010): 556-92. [CrossRef]

10. Marinoble, Rita M. "Elementary school teachers: Homophobia reduction in a staff development context." In Overcoming Heterosexism and Homophobia: Strategies that Work. Edited by James Thomas Sears and Walter L. Williams. New York: Colombia University Press, 1997, pp. 249-60.

11. McCabe, Paul C., and Florence Rubinson. "Committing to social justice: The behavioral intention of school psychology and education trainees to advocate for lesbian, gay, bisexual, and transgendered youth." School Psychology Review 37 (2008): 469-86.

12. Morgan, Daniel J. “Knowledge and Attitudes of Preservice Teachers towards Students Who Are Gay, Lesbian, Bisexual, or Transgendered." Ph.D. Dissertation, Special Education, University of North Texas, Denton, TX, USA, December 2003.

13. Riggs, Angela D., Amy R. Rosenthal, and Tina Smith-Bonahue. "The impact of a combined cognitive-affective intervention on pre-service teachers' attitudes, knowledge, and anticipated professional behaviors regarding homosexuality and gay and lesbian issues." Teaching and Teacher Education 27 (2011): 201-9. [CrossRef]

14. Schniedewind, Nancy, and Karen Cathers. "Becoming allies for each other: An inclusive approach for confronting heterosexism in schools." Equity E Excellence in Education 36 (2003): 184-93. [CrossRef]

15. Vavrus, Michael. "Sexuality, schooling, and teacher identity formation: A critical pedagogy for teacher education." Teaching and Teacher Education 25 (2009): 383-90. [CrossRef]

16. Goldstein, Tara, Vanessa Russell, and Andrea Daley. "Safe, positive and queering moments in teaching education and schooling: A conceptual framework." Teaching Education 18 (2007): 183-99. [CrossRef]

17. Bryk, Anthony S., Penny Bender Sebring, Elaine Allensworth, John Q. Easton, and Stuart Luppescu. Organizing Schools for Improvement: Lessons from Chicago. Chicago: University of Chicago Press, 2010.

18. Pianta, Robert C., Bridget K. Hamre, and Joseph P. Allen. "Teacher-student relationships and engagement: Conceptualizing, measuring, and improving the capacity of classroom interactions." In Handbook of Research on Student Engagement. New York: Springer, 2012, pp. 365-86.

19. Broido, Ellen M. "The development of social justice allies during college: A phenomenological investigation." Journal of College Student Development 41 (2000): 3-18.

20. Evans, Nancy J., and Vernon A. Wall. Beyond Tolerance: Gays, Lesbians and Bisexuals on Campus. Alexandria: American Association for Counseling and Development, 1991.

21. Gelberg, Susan, and Joseph T. Chojnacki. “Developmental Transitions of Gay/Lesbian/Bisexual-Affirmative, Heterosexual Career Counselors." The Career Development Quarterly 43 (1995): 267-73. [CrossRef]

22. Ji, Peter, and Ken Fujimoto. "Measuring Heterosexual LGBT Ally Development: A Rasch Analysis." Journal of Homosexuality 60 (2013): 1695-725. [CrossRef] [PubMed]

23. Jones, K. Nicole, Melanie E. Brewster, and Jacob A. Jones. "The creation and validation of the LGBT Ally Identity Measure." Psychology of Sexual Orientation and Gender Diversity 1 (2014): 181-95. [CrossRef]

24. Washington, Jamie, and Nancy J. Evans. "Becoming an ally." Beyond Tolerance: Gays, Lesbians, and Bisexuals on Campus (1991): 195-204.

25. Edwards, Keith E. "Aspiring social justice ally identity development: A conceptual model." NASPA Journal 43 (2006): 39-60.

26. Duhigg, Julie M., Sharon S. Rostosky, Barry E. Gray, and Mary K. Wimsatt. “Development of heterosexuals into sexual-minority allies: A qualitative exploration." Sexuality Research and Social Policy 7 (2010): 2-14. [CrossRef]

27. Goldstein, Susan B., and Denise S. Davis. "Heterosexual allies: A descriptive profile." Equity E Excellence in Education 43 (2010): 478-94.

28. Payne, Elizabethe C., and Melissa J. Smith. "Safety, celebration, and risk: Educator responses to LGBTQ professional development." Teaching Education 23 (2012): 265-85. [CrossRef]

29. Robinson, Kerry H., and Tania Ferfolja. "Playing it up, playing it down, playing it safe: Queering teacher education." Teaching and Teacher Education 24 (2008): 846-58. [CrossRef]

30. Mohr, Jonathan J. "Heterosexual Identity and the Heterosexual Therapist: An Identity Perspective on Sexual Orientation Dynamics in Psychotherapy." The Counseling Psychologist 30 (2002): 532-66. [CrossRef]

31. Airton, Lee. "Leave 'those kids' alone: On the conflation of school homophobia and suffering queers." Curriculum Inquiry 43 (2013): 532-62. [CrossRef] 
32. Kumashiro, Kevin K. Troubling Education: Queer Activism and Antioppressive Pedagogy. New York: Psychology Press, 2002.

33. Miller, Janet L. “Otherness.” In The SAGE Encyclopedia of Qualitative Research Methods. Edited by Lisa M. Given. Los Angeles: SAGE, 2008, pp. 588-91.

34. Stafford, Anika Nicole. “'I FEEL LIKE A GIRL INSIDE': Possibilities for Gender and Sexual Diversity in Early Primary School." BC Studies 189 (2016): 9-29.

35. Talburt, Susan, Eric Rofes, and Mary Louise Rasmussen. "Introduction: Transforming discourses of queer youth and educational practices surrounding gender, sexuality, and youth." In Youth and Sexualities: Pleasure, Subversion and Insubordination in and out of Schools. Edited by Susan Talburt, Eric Rofes and Mary Louise Rasmussen. New York: Palgrave Macmillan, 2004, pp. 1-13.

36. Robinson, Kerry H. "'Queerying' gender: Heteronormativity in early childhood education." Australian Journal of Early Childhood 30 (2005): 19-28.

37. Finkel, Melinda J., Ragnar D. Storaasli, Anthony Bandele, and Vivian Schaefer. "Diversity training in graduate school: An exploratory evaluation of the Safe Zone project." Professional Psychology: Research and Practice 34 (2003): 555-61. [CrossRef]

38. Evans, Nancy J., and Todd K. Herriott. "Freshmen impressions: How investigating the campus climate for LGBT students affected four freshmen students." Journal of College Student Development 45 (2004): 316-32. [CrossRef]

39. Waterman, Amy D., James D. Reid, Lauren D. Garfield, and Sandra J. Hoy. "From curiosity to care: Heterosexual student interest in sexual diversity courses." Teaching of Psychology 28 (2001): 21-26. [CrossRef]

40. Harro, Roberta L. "Cycle of socialization." In Readings for Diversity and Social Justice. Edited by Maurianne Adams, Warren Blumenfeld, Carmelita (Rosie) Castañeda, Heather W. Hackman, Madeline L. Peters and Ximena Zúñiga. New York: Routledge, 2010, p. 15.

41. Strauss, Anselm, and Juliet Corbin. Basics of Qualitative Research. Newbury Park: Sage, 1990, vol. 15.

42. Tuck, Eve. "Suspending damage: A letter to communities." Harvard Educational Review 79 (2009): 409-28. [CrossRef]

43. Talburt, Susan. "Constructions of LGBT youth: Opening up subject positions." Theory into Practice 43 (2004): 116-21. [CrossRef]

44. Hackford-Peer, Kim. "In the name of safety: Discursive positionings of queer youth." Studies in Philosophy and Education 29 (2010): 541-56. [CrossRef]

45. Knowles, Malcolm S., Elwood F. Holton, III, and Richard A. Swanson. The Adult Learner: The Definitive Classic in Adult Education and Human Resource Development. New York: Routledge, 2014.

46. Kolb, David A. Experiential Learning: Experience as the Source of Learning and Development. Upper Saddle River: FT Press, 2014.

47. Waters, Rhian. "Understanding allyhood as a developmental process.” About Campus 15 (2010): 2-8. [CrossRef]

48. Bransford, John D., Ann L. Brown, and Rodney R. Cocking. “How people learn: Brain, Mind, Experience, and School." 2000. Available online: http:/ / www.colorado.edu/MCDB/LearningBiology/readings/Howpeople-learn.pdf (accessed on 16 September 2016).

(C) 2017 by the authors; licensee MDPI, Basel, Switzerland. This article is an open access article distributed under the terms and conditions of the Creative Commons Attribution (CC BY) license (http:/ / creativecommons.org/licenses/by/4.0/). 